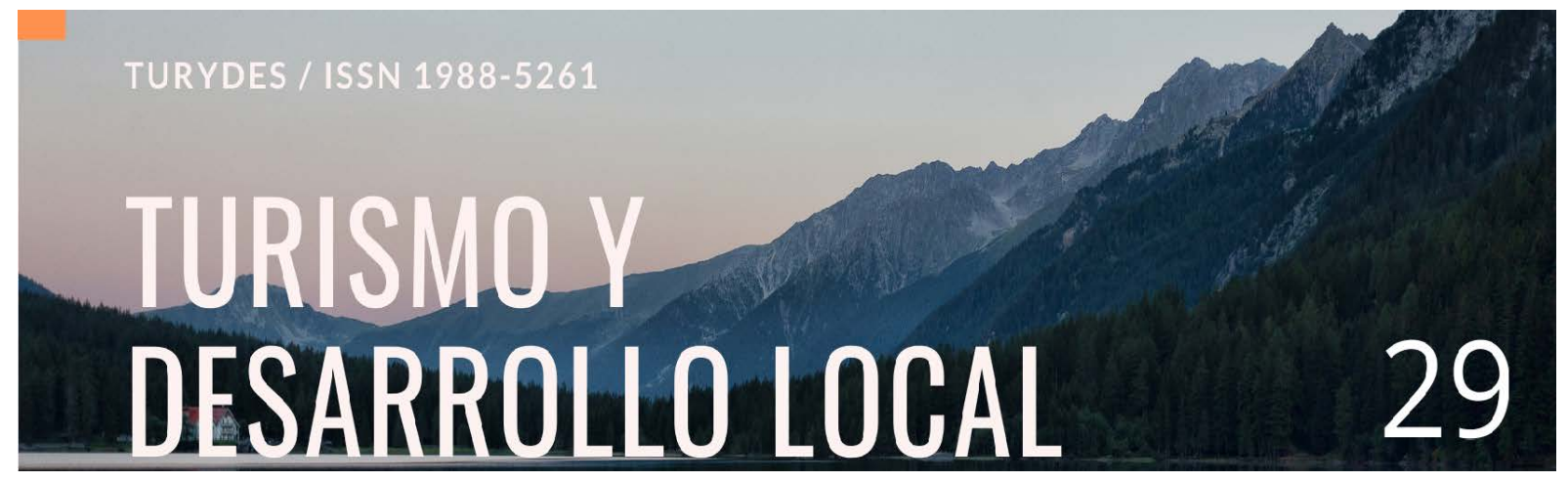

\title{
DEL RECURSO ATRACTIVO A LA EXPERIENCIA TURÍSTICA
}

\author{
Universidad Laica Eloy Alfaro de Manabí, Ecuador \\ mabelfont@yahoo.es \\ Cristobal Alexei Abreu García ${ }^{2}$ \\ Universidad de Matanzas, Cuba
}

Para citar este artículo puede utilizar el siguiente formato:

Mabel Font Aranda y Cristobal Alexei Abreu García: "Del recurso atractivo a la experiencia turística", Revista Turydes: Turismo y Desarrollo, n. 29 (diciembre/dezembro 2020). En línea:

https://www.eumed.net/es/revistas/turydes/vol-13-no-29-diciembre-dezembro-2020/experienciaturistica

\section{RESUMEN}

El trabajo tiene como objetivo discernir conceptos vinculados a la actividad turística como son recursos / atractivos, productos, ofertas y experiencias turísticas, cuyos conocimientos son importantes para el desarrollo de los procesos de gestión. Se destaca, la necesidad de transitar en la práctica, hacia una vivencia inolvidable de los excursionistas y turistas; que condicione el regreso al disfrute, una y otra vez de la experiencia vivida. La diferenciación de estos conceptos, antes de iniciar la gestión, garantiza una configuración adecuada de los procesos y actividades en el itinerario del consumo del turista. La construcción del trabajo es realizada principalmente, mediante contraste de opiniones vertidas por diferentes autores, a través del empleo de métodos como revisión bibliográfica, analítico sintético y la modelación. La información recabada se compila, organiza y describe en el documento. Concluyendo que, si bien, los recursos atractivos son la materia prima de la actividad turística, alrededor de los cuales se configura el producto y la oferta; los cambios de paradigmas exigen hoy, el diseño de experiencias donde la inserción del visitante

\footnotetext{
${ }^{1}$ Doctora en Ciencias Geográficas por la Universidad de La Habana. Master en Gestión Turística Mención Comercialización por la Universidad de Matanzas. Master en Análisis Ambiental y Ordenamiento Territorial por la Universidad de La Habana. Postdoctorada en Gestión integrada e inteligente de destinos turísticos por la Universidad de Islas Baleares - Fundación Carolina. Profesora Titular Principal Universidad Laica Eloy Alfaro de Manabí (ULEAM). Ecuador.

${ }_{2}$ Especialista en Derecho y Licenciado en Derecho por la Universidad Marta Abreu de Las Villas. Profesor Instructor de la Universidad de Matanzas, Cuba.
} 
en las actividades, requiera el uso de todos los sentidos para que convierta la estancia en memorable.

PALABRAS CLAVE: recurso turístico, atractivo turístico, producto turístico, oferta turística, experiencia turística

FROM THE ATTRACTIVE RESOURCE TO THE TOURIST EXPERIENCE

\section{ABSTRACT}

The objective of the work is to discern concepts related to tourist activity such as resources / attractions, products, offers and tourist experiences, whose knowledge is important for the development of management processes. It stands out, the need to move in practice, towards an unforgettable experience for hikers and tourists; that conditions the return to enjoyment, again and again, of the lived experience. The differentiation of these concepts, before starting the management, guarantees an adequate configuration of the processes and activities in the tourist consumption itinerary. The construction of the work is carried out mainly, by contrasting opinions expressed by different authors, through the use of methods such as bibliographic review, synthetic analytical and modeling. The information collected is compiled, organized and described in the document. Concluding that, although attractive resources are the raw material of tourist activity, around which the product and the offer are configured; Today, paradigm shifts require the design of experiences where the insertion of the visitor in the activities requires the use of all the senses to make the stay memorable.

KEYWORDS: tourist resource, tourist attraction, tourist product, tourist offer, tourist experience

\section{INTRODUCCIÓN}

La naturaleza y el alcance de los conceptos utilizados pueden determinar el enfoque de la gestión, quién o qué se gestiona, dónde se encuentran las prioridades de gestión y dónde se pueden encontrar soluciones (Pearce, 2014, p.141). Desde la mirada anterior, adquiere importancia en la gestión turística, discernir entre conceptos claves como lo son los recursos / atractivos, productos, ofertas y experiencias turísticos. Esto implica, ascender para sobrepasar las expectativas del visitante, en el itinerario del consumo turístico. Tales criterios tienen su fundamento en los postulados de Joseph Pine y James Gilmore, quienes plantearon la progresión del valor económico, desde las materias primas indiferenciadas; pasando por bienes y servicios, hasta el nivel superior de las experiencias, personalizadas y ajustadas a las necesidades del cliente para la creación de un evento memorable (Pine \& Gilmore,1998).

Pero, en turismo como actividad de servicio, si bien refleja un tránsito; el punto de partida son los atractivos, que se derivan de los recursos turísticos distintivos, porque exigen tener poder de atracción, ellos constituyen la materia prima de la actividad. Para la puesta en valor de los recursos atractivos, se requiere de accesibilidad, infraestructuras, servicios y actividades que configuran el producto. La oferta representa la agrupación de estos últimos, la amalgama de componentes que 
se ajusta a determinados segmentos, fechas, intereses por un precio determinado. La experiencia representa un traje a la medida del consumidor, con énfasis en las motivaciones, los sentimientos, las vivencias genuinas y peculiares.

A partir del posicionamiento señalado, la figura 1 sintetiza la secuencia referida.

Figura 1. Del atractivo a la experiencia

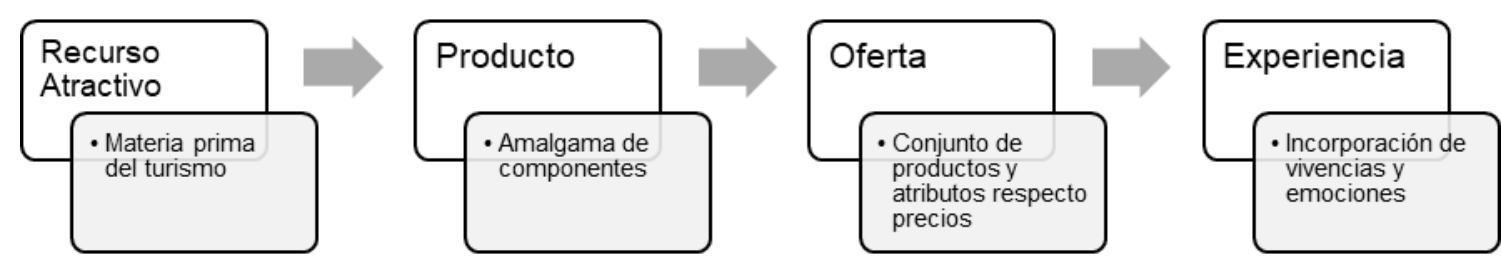

Fuente: Elaboración propia.

Hay muchos sectores que componen la experiencia de la economía (Pine \& Gilmore, 2012, p. 23) como películas, eventos deportivos, festivales de música, galerías de arte, videojuegos, centros de información corporativa, ferias comerciales, atracciones turísticas, complejos hoteleros, clubes de membresía, otros. Las experiencias son una forma distinta de producción económica y, como tales, son la clave para promover la prosperidad. Los bienes y los servicios existen fuera del comprador individual, las experiencias suceden dentro de él (Pine \& Gilmore, 2012, p. 27). Estos posicionamientos se han anclado en el turismo en la actualidad y con ello coinciden Ballina, 2018; Riquelme, 2019; Mogollón, González, \& Cerro, 2020; Wang \& Chen, 2020; Żemła \& Siwek, 2020.

El trabajo tiene como objetivo discernir conceptos vinculados a la actividad turística como son recursos / atractivos, productos, ofertas y experiencias turísticas, cuyos conocimientos tienen importancia para el desarrollo de los procesos de gestión. Se destaca, la necesidad de transitar en la práctica, hacia una vivencia inolvidable de los excursionistas y turistas; que condicione el regreso al disfrute, una y otra vez de la experiencia vivida

\section{La materia prima del turismo: los recursos / atractivos turísticos}

La base del desarrollo del turismo son los recursos turísticos, que, de acuerdo a su atracción y singularidad, influyen en el turista para la selección del destino. Según Vera, López Palomeque, Marchena y Antón; los recursos de atracción turísticos son las piezas motivadoras de toda la circulación del sistema turístico, tanto naturales como creados ad hoc, por ejemplo, productos recreativos y de ocio temáticos (1997, p. 40). En general, la principal virtud de los atractivos es su capacidad para cautivar y atraer a los turistas (SECTUR, 2001 p. 16). Señala Ballina (2018) que los recursos turísticos son los atributos territoriales susceptibles de generar experiencias al turista, a diferencia de estos, puede haber muchos atractivos; este autor apela por el término recurso y no atractivo.

Respecto la materia prima del turismo, refiere Boullón (2006, p. 46) que, a diferencia de la industria, en el turismo los atractivos, deben permanecer intactos o restituirse la pérdida de cualidades por diferentes causas en el paso del tiempo. Además, en el turismo la materia prima no puede transportarse, porque es inamovible, ubicándose la planta turística e infraestructuras en su 
radio de acción, cuestiona el término recurso turístico. Por parte de Rodríguez Fariña (2005, p. 25) los recursos turísticos son todos los elementos disponibles en un espacio dado (de origen natural o creados por el hombre), susceptibles de su uso y aprovechamiento con fines turísticos. Desde la mirada de Vera et al. (1997, p. 61), el espacio es soporte, recurso y factor a la vez por su condición geográfica: magnitud espacial y atributos de carácter cualitativo de valor intrínseco (natural o cultural) derivado de la valoración cualitativa que le otorga la sociedad en cada momento histórico, lo cual conduce a la "adecuación" de los recursos o atractivos y a su conversión en producto y oferta, objeto de venta y consumo turístico.

Los recursos turísticos suelen calificarse en naturales y culturales; los atributos de la naturaleza de un determinado territorio o los desarrollados por sus habitantes, de forma histórica o actual (Ballina, 2018). Pero para la gestión, es interesante contemplar varias clasificaciones de los recursos / atractivos turísticos (figura 2). Cuanto más únicos y frágiles, más atractivos, por eso su protección y buena gestión ha de ser una prioridad. De lo contrario, se pone en peligro el potencial del lugar como destino turístico. En este trabajo, se considera factible el uso de ambos términos, el recurso es potencial, no todos tienen atractivo; cuando genera motivación por desplazarse hacia él y se crean las condiciones para el disfrute, se convierten en atractivos turísticos. También, es válido estudiar aquellos aspectos distintivos de los recursos geográficos naturales y culturales, que estimulan el desplazamiento. Así, una playa como Varadero en Matanzas, Cuba; constituye un recurso turístico, que atrae por la transparencia de sus aguas, arenas blancas y pendientes predominantemente suaves, que la convierte en una extensa piscina natural. La playa Varadero es un atractivo focal y principal motivo de desplazamiento hacia allí.

Figura 2. Clasificación de los recursos/atractivos turísticos

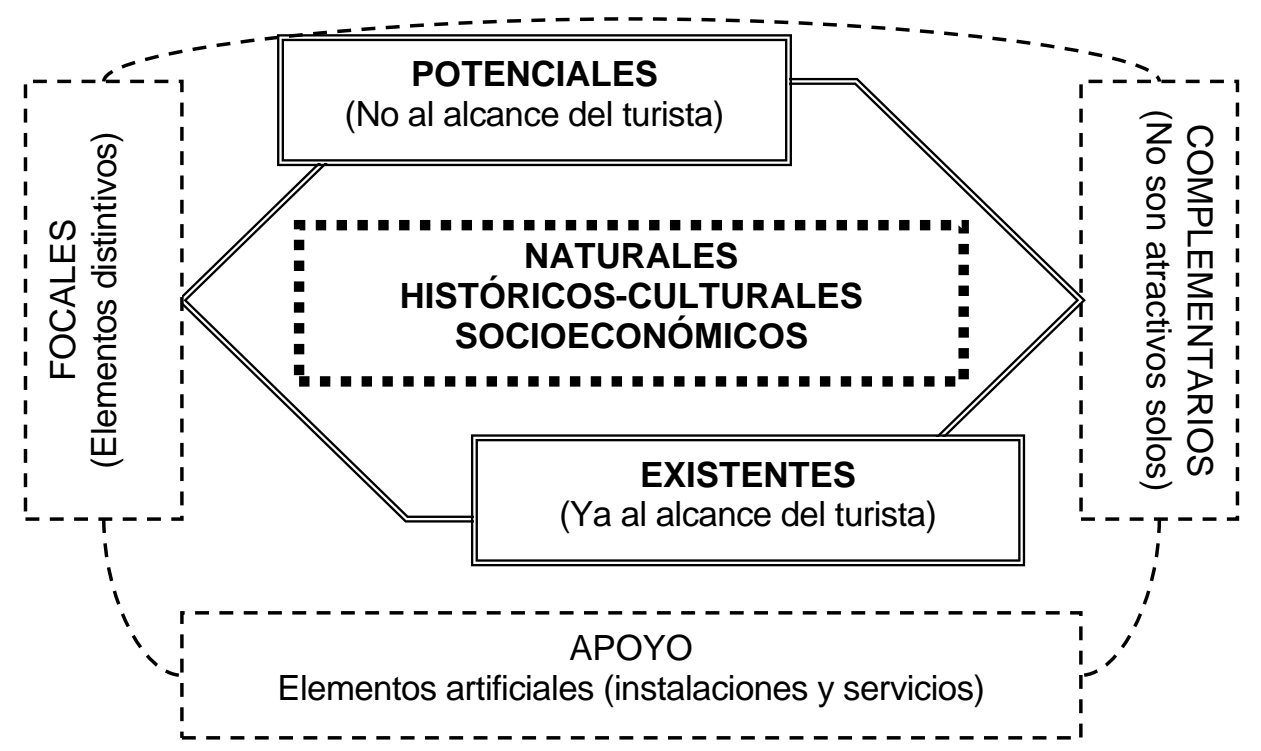

Fuente: Font Aranda, 2010

Para conocer cuáles y cuántos son los recursos turísticos que se disponen en un territorio y sus características, es necesario realizar un inventario. Éste representa un instrumento valioso 
para la planificación turística, en cualquier ámbito, al mismo tiempo que sirve como punto de partida para realizar evaluaciones y establecer las prioridades necesarias para el desarrollo local, regional o nacional. Las potencialidades identificadas y reconocidas hacen referencia a la diversidad y a la ventaja comparativa. A partir del reconocimiento del patrimonio local, de la identificación y evaluación de los recursos / atractivos turísticos y de la diversidad endógena de las localidades, es posible descubrir otras alternativas de desarrollo. Un inventario de recursos turísticos dice Ballina (2018) es una perfecta descripción de los mismos, su ubicación geográfica, las posibles restricciones de uso por temporalidad o por capacidad, así como de los servicios que incorpora o que se encuentran próximos al mismo. El inventario turístico aporta elementos sólidos para detectar con gran certeza las ventajas, oportunidades, debilidades y amenazas de los recursos turísticos y las actividades a realizar (SECTUR, 2001 p. 16).

Para ejemplificar, se citan recursos / atractivos turísticos del cantón Puerto López en Manabí, Ecuador. Entre los de carácter natural se destacan: Parque Nacional Machalilla, Playa Los Frailes, Bosque Bola de Oro (Bosque bajo montano localizado en la estribación de la Cordillera ChongónColonche), Isla La Plata (con gran diversidad de especies de aves). Ejemplos de recursos / atractivos turísticos de tipo cultural son: Área Arqueológica Agua Blanca (museo de sitio, urnas funerarias, ruinas arqueológicas), Museo arqueológico Salango, Fiestas Patronales de San Pedro y San Pablo, Festival de Observación de Ballenas, Festival de la Balsa Manteña, Festival Gastronómico Cultural y Ancestral.

\section{El producto turístico y la oferta turística}

El producto es la piedra angular de todo el sistema, es cualquier cosa que se ofrece al mercado para satisfacer un deseo o una necesidad. Los productos turísticos son en muchos casos, una combinación de todos los elementos o atributos (Serra, 2011). Los productos característicos del turismo son aquellos que cumplen uno o ambos de los siguientes criterios OMT (2020, p.127): 1. El gasto turístico en el producto, debería representar una parte importante del gasto total turístico (proporción gasto/demanda). 2. El gasto turístico en el producto debería representar una parte importante de la oferta del producto en la economía (proporción que corresponde a la oferta, la cual se reduce si no hay visitantes). Otros autores, expresan su definición de producto turístico (tabla1). 
Tabla 1. Selección de definiciones sobre producto turístico

\begin{tabular}{|c|c|}
\hline Autor/ año & Definición de producto turístico \\
\hline $\begin{array}{l}\text { Bigné et al., } \\
2000 \text {, p.28 }\end{array}$ & $\begin{array}{l}\text { "Todo aquello que puede ser ofrecido al mercado para satisfacer una } \\
\text { necesidad o deseo, sea tangible o intangible". }\end{array}$ \\
\hline $\begin{array}{l}\text { SECTUR, } 2001 \\
\text { p. 10) }\end{array}$ & $\begin{array}{l}\text { "Es el conjunto de componentes tangibles e intangibles que incluye: recursos y } \\
\text { atractivos turísticos, equipamientos e infraestructuras, servicios, actividades } \\
\text { recreativas, imágenes y valores simbólicos, que ofrecen beneficios capaces de } \\
\text { atraer a grupos determinados de consumidores, porque satisfacen las } \\
\text { motivaciones y expectativas relacionadas con su tiempo libre". }\end{array}$ \\
\hline $\begin{array}{l}\text { Kotler et al., } \\
2011 \text {, p. } 290\end{array}$ & $\begin{array}{l}\text { "Cualquier cosa que pueda ofrecerse a un mercado para atención, adquisición, } \\
\text { uso o consumo que pueda satisfacer un deseo o necesidad. Incluye objetos } \\
\text { físicos, servicios, lugares, organizaciones e ideas". }\end{array}$ \\
\hline Ballina, 2018 & $\begin{array}{l}\text { "Agrupa los recursos territoriales según una determinada combinación } \\
\text { tematizada (elementos centrales), añadiendo una serie de componentes } \\
\text { tangibles e intangibles (elementos periféricos y complementarios), para la } \\
\text { satisfacción del público objetivo al que fueron diseñados" }\end{array}$ \\
\hline $\begin{array}{l}\text { OMT, 2019, p. } \\
19\end{array}$ & $\begin{array}{l}\text { "Es una combinación de elementos materiales e inmateriales, como los } \\
\text { recursos naturales, culturales y antrópicos, así como los atractivos turísticos, } \\
\text { las instalaciones, los servicios y las actividades en torno a un elemento } \\
\text { específico de interés, que representa la esencia del plan de marketing de un } \\
\text { destino y genera una experiencia turística integral, con elementos } \\
\text { emocionales, para los posibles clientes". }\end{array}$ \\
\hline
\end{tabular}

Fuente: Elaboración propia.

La figura 3, sintetiza y modela el concepto de producto turístico desde la interpretación teórico - práctica y manifiesta coherencia con los autores Bigné et al., 2000, p.28; SECTUR, 2001 p. 10; Kotler et al., 2011, p. 290; Ballina, 2018; OMT, 2019, p. 19 expresados en la tabla 1. 
Figura 3. Componentes del producto turístico.

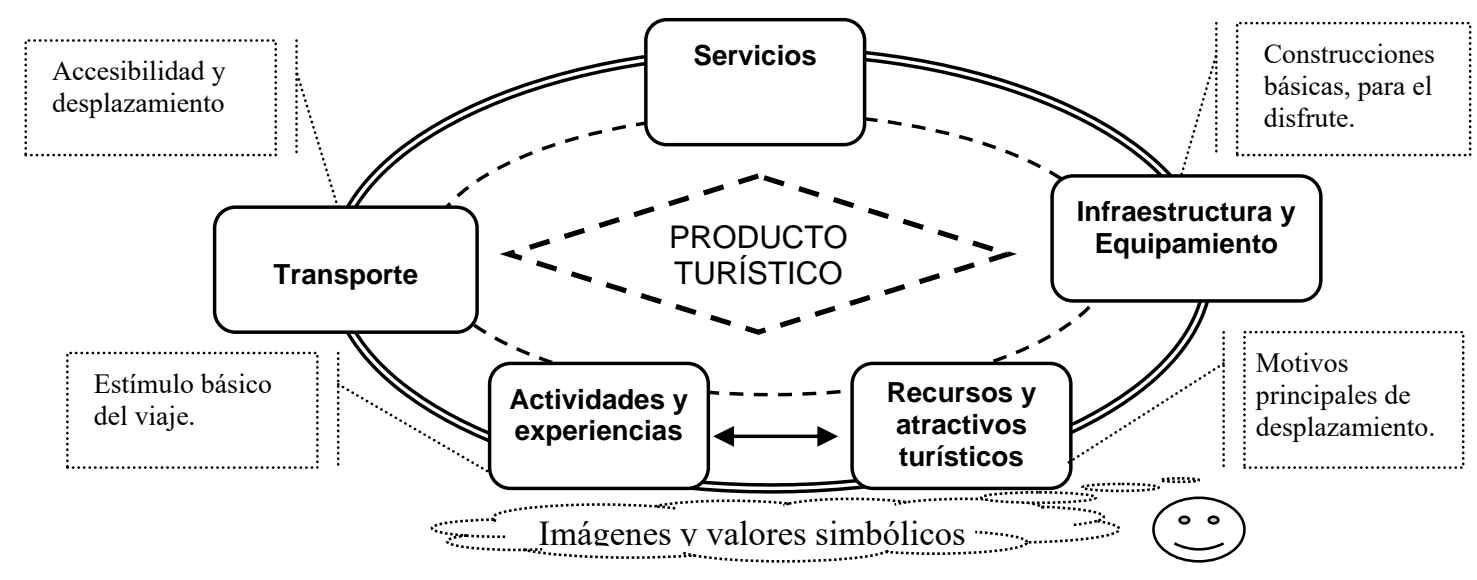

Fuente: Font Aranda, 2010.

Los profesionales del turístico tienen que pensar en el producto o servicio desde cuatro niveles: el producto o beneficio central, el producto esperado, el producto de apoyo y el producto aumentado (Kotler et al., (2011, p. 290). Además, existen diversas clasificaciones de productos, Martín (2003) citado por Matos, (2005), señala que hay tres grandes grupos: los viajes, las facilidades" o equipamiento, los territorios o integrado. Los "viajes" representan las entregas al momento de la compra, antes de iniciarse el viaje en soporte papel o informático, que representa los futuros servicios a recibir. Las "facilidades" o equipamiento", incluyen variedad de servicios como: alimentos y bebidas, alojamiento, formas de transportación, entidades dedicadas a la recreación, ocio o desarrollo de otras actividades turísticas, conteniendo centros de información. Los productos turísticos territoriales se crean sobre un espacio geográfico o territorio y su máxima expresión son los destinos turísticos.

Según Matos (2005) los productos turísticos territoriales, a su vez pueden ser: complejo turístico en un entorno geográfico delimitado, vinculado a un atractivo natural o cultural. El polo turístico es una delimitación geográfica, con marca propia, que acoge instalaciones subordinadas o no, a diferentes entidades. El destino específico, también con delimitación geográfica específica, posee una amplia gama de atractivos e instalaciones orientados a varios segmentos de mercados. Señala Bigné et al. (2000) que, los destinos turísticos son combinaciones de productos turísticos que ofrecen una experiencia integrada a los turistas.

Los productos turísticos territorios, consideran la región turística y el destino País como el conjunto de regiones y los polos turísticos, son una marca sujeta a la comunicación promocional turística. En el destino la combinación de atractivos, instalaciones y servicios, facilidades y accesibilidad, imagen del destino ajustado a precio para el consumidor; se expresa como producto turístico integrado. Como concepto percibido, se interpreta subjetivamente por los consumidores, en función de las peculiaridades del itinerario del visitante (Bigné et al., 2000; Matos, 2005; Rodríguez Fariña, 2005; Boullón, 2006; Pearce, 2014; Birenboim, 2015; Ballina, 2018). 
Para la OMT son normalmente productos característicos del turismo; los que equivalen al más coloquial «sector turístico»: alojamiento para visitantes, actividades de provisión de alimentos y bebidas, transporte de pasajeros por ferrocarril, transporte de pasajeros por carretera, transporte de pasajeros por agua, transporte aéreo de pasajeros, alquiler de equipos de transporte, actividades de agencias de viajes y de otros servicios de reservas, actividades culturales, actividades deportivas y recreativas, comercio al por menor de bienes característicos del turismo, específicos de cada país, otras actividades peculiares del turismo, específicas de cada país (2020, p.121,130). También, dependiendo de las tipologías del espacio donde se desarrolla el producto turístico puede ser urbano, cultural, rural, natural, de salud, entre otros.

Toda economía se define por su oferta económica predominante: lo que un comprador obtiene de un vendedor a cambio de dinero (Pine \& Gilmore, 2012, p. 22). Conjunto de productos turísticos y servicios puestos a disposición del usuario turístico en un destino determinado, para su disfrute y consumo (Sancho, 1998, p. 47). Una oferta es la cantidad de mercancía o servicio que entra en el mercado consumidor a un precio dado y por un periodo dado (Boullón, 2006, p. 34). Una oferta de mercado incluye mucho más que productos físicos o servicios (Kotler Philip, et al. 2011). Desde el punto de vista de la oferta, teniendo en cuenta su relación con el Sistema de Cuentas Nacionales, las estadísticas de turismo utilizan el «establecimiento» (OMT; 2020, p.129).

La oferta turística constituye una adecuación del producto, que se ajusta a los intereses de la demanda. Para que el visitante permanezca o se desplace, requiere facilidades y servicios, supliendo así, sus necesidades y deseos, todo a determinados precios, en un período determinado de tiempo.

Siguiendo el curso de los ejemplos expresados en el epígrafe anterior, se constata en la playa de Varadero en Cuba, la presencia de más de 50 hoteles, además de viviendas de renta y negocios de gastronomía. En los $22 \mathrm{~km}$ de la playa se realizan actividades de diferentes tipos, paseos en diversos medios náuticos, prácticas deportivas, bailo terapia, competencias, juegos participativos, y muchas otras alternativas para gustos de diversos segmentos de mercados. En el predominio de los hoteles, el régimen de estancia es Todo Incluido, abarcando también la animación, la cual, en el destino, tiene un rol fundamental. Los precios varían estacionalmente y de acuerdo a la categoría del alojamiento.

En Puerto López, Ecuador las ofertas principales están relacionadas con la observación de ballenas, los viajes en lancha a la Isla de la Plata que combinan la práctica de pesca deportiva, kayak y snorkeling; buceo en los alrededores de la Isla Salango, el Tour Machalilla y Agua Blanca, recorridos por el Sendero Bola de Oro y se distingue la diversidad de ofertas gastronómicas locales. Los precios están marcados por la estacionalidad, entre otros factores comunes.

Se concluye que, la oferta expresa el ajuste a las exigencias del consumidor, también manifiesta la combinación de varios productos y la incorporación de otros atributos como el precio competitivo y la puesta en el mercado en un tiempo determinado. 


\section{La experiencia turística}

El turismo es una actividad que cautiva los sentidos e invita al conocimiento y a la vivencia de nuevas experiencias (Almela, 2017, p. 67). Las motivaciones por los viajes han ido cambiando a través del tiempo. En 1998, Joseph Pine y James Gilmore anunciaron la llegada de un nuevo paradigma de consumo denominado experience economy, donde lo que determina no es solo el coste o beneficio, sino las vivencias, experiencias, sensaciones y emociones (Mogollón, González \& Cerro, 2020, p. 64). Y desde antes (citan Pine \& Gilmore); Erving Goffman en 1959, Toffler, 1970 y Jay Ogilvy 1985 se habían referido a la "industria experiencia" y experiencias vividas". Al hablar de experiencias la describen como: memorable, creado, individualizado, coexperimentado, participación en la creación, contenidos, sensaciones, sensorial, social, conocimiento. "Las experiencias son solo eventos memorables por las transformaciones que permiten" (Pine \& Gilmore, 2012, p. 23). Desde una visión individual, en 1982 Holbrook \& Hirschman, (p.132) señalaban que la experiencia es "un acontecimiento personal con un importante significado emocional, basado en la interacción con los estímulos que producen los productos o servicios consumidos"

Tales paradigmas, adquieren relevancia en el turismo, como genuina actividad de servicios, que tiene en fin la construcción de nuevas vivencias, diferentes a los lugares de origen. Expresa SERNATUR que, cada vez más frecuentemente, una nueva dimensión del consumo se presenta en el mundo: más allá de adquirir bienes y servicios, lo que ahora se ofrece es "vivir una experiencia" que aporte novedad a las rutinas cotidianas (2016, p. 10). Los turistas contemporáneos se concentran más en sus experiencias y emociones que en simples visitas turísticas y a monumentos (Żemła \& Siwek, 2020, p. 1). Los turistas son buscadores de experiencias, que encuentran no solo "tesoros" físicos, sino también sensaciones agradables, creándose así una especie de conexión emotiva entre turista y destino (Almela, 2017, p. 74).

Existen diferentes enfoques de experiencias: una vivencia de carácter sensorial, vinculado a las expectativas y la condición de mercancía, como producto de consumo mediante promoción utilitaria de los patrimonios culturales, identitario y naturales de los espacios y los destinos turísticos (Riquelme, 2019, p. 227). La estimulación de los sentidos constituye uno de los grandes ejes de la experiencia turística y así se refleja de forma explícita en el lenguaje del turismo. La percepción es especialmente relevante para recrear la experiencia turística e integrar al turista en el escenario del viaje (Almela, 2017, p. 64, 73). La emodiversidad es particularmente relevante para el turismo, no se limita a las emociones positivas, también las negativas. La emodiversidad refleja las ricas y complejas experiencias emocionales de los turistas cuando viajan (Wang, Hou, \& Chen, 2020, p. 4).

Armand Frémont (1976) y Cuy Di Meo (1991), sentaron las bases conceptuales del espacio vivido, destacando que está asociado a las experiencias y representaciones subjetivas, vinculado a los intercambios sociales que integra (Riquelme, 2019, p. 225). A través de la atribución de 
significado recíproca y reflexiva, la experiencia de viaje puede representar rasgos de carácter y creencias morales, el compromiso con las relaciones y la pertenencia social a grupos específicos, y la experiencia con el mundo (Kuhn, 2020, p. 499). En lugar de simplemente vender emociones positivas por agradar, los gerentes de turismo deberían comenzar a reconocer la importancia de crear una "experiencia de búsqueda de emodiversidad (Wang, Hou, \& Chen, 2020, p. 14). Żemła \& Siwek subrayaron el papel clave de la autenticidad existencial en la creación de experiencias turísticas (2020, p. 15).

En la cadena de valor del turismo, en el itinerario del consumo turístico y en los diferentes productos y ofertas turísticos, se crean experiencias afines y disímiles. El diccionario de definiciones turísticas de la OMT (2019) muestra ejemplos de esta variedad: a nivel de destino se genera una experiencia integral, en el turismo rural los productos están vinculados a experiencias con las actividades de naturaleza, la agricultura, las formas de vida y las culturas rurales, la pesca con caña y la visita a lugares de interés. La experiencia del turismo de aventura, significa algún tipo de riesgo, esfuerzo físico o mental. Para el turismo gastronómico las experiencias son auténticas, tradicionales, innovadoras como por ejemplo la asistencia a clases de cocina. El turismo urbano, engloba experiencias diversas relacionadas con: cultura, arquitectura, tecnología, las vivencias sociales, los negocios, por citar algunos ejemplos. Las experiencias de aprendizaje, de crecimiento intelectual y desarrollo de habilidades; son claves en el turismo educativo. Otro ejemplo plantea Kuhn: los significados simbólicos de los souvenirs como representaciones de la experiencia de viaje, permiten a los turistas reflexionar y comunicar el autoconcepto, los roles turísticos idealizados y las creencias simbólicas a los demás sociales (2020, p. 500).

La experiencia turística no se puede transferir (Sancho,1998, p.369). El tiempo y espacio en los que tienen lugar las experiencias, son precisados y con las nuevas tecnologías los Sistemas de Posicionamiento Global y Wi-Fi, como ejemplos, mejoran de las investigaciones (Birenboim, A. 2015 , p. 3), pero, también se reconstruyen las experiencias de los turistas y se enriquece su vivencia. Señalan Pine \& Gilmore (2012, p. 22) "la autenticidad se ha convertido en la nueva sensibilidad del consumidor".

Los destinos pueden mejorar sus estrategias de marketing centrándose en la oferta de experiencias, puesto que las estrategias de marketing tradicionales, enfocadas en la venta de productos o servicios, han perdido eficacia (Mogollón, González \& Cerro, 2020, p. 63). Los turistas y excursionistas a partir del producto eligen un destino, utilizando tanto la imagen cognitiva como la afectiva, donde las experiencias únicas con el destino permiten su posicionamiento (OlguínNegrete \& Cuevas-Contreras, 2019, p. 168). La nueva tendencia del turismo inteligente, ha sido abordada por diversos autores, los que señalan que "un destino turístico se convierte en inteligente cuando hace un uso intensivo de la infraestructura tecnológica con el fin de (1) mejorar la experiencia del turista y (2) mejorar el proceso de toma de decisiones" (Celdrán-Bernabeu, Mazón 
\& Sánchez, 2018, p. 53 cita a Lamsfus, Martín, Alzua-Sorzabal y Torres-Manzanera, 2015; Boes, Buhalis y Inversini, 2015; Koo, Shin, Gretzel, Hunter y Chung, 2016).

Fuentes, Moreno-Gil, González y Ritchie (2015, p. 75) determinaron siete dimensiones de la experiencia turística que son: Involucración del turista con el entorno y la comunidad, Shock sensorial ya que apela a los cinco sentidos, Autenticidad por la vinculación con el entorno inmediato, Diversión al crear placer, Sociabilidad es compartir y participar en una comunidad, Personalización por la libertad y control para elegir lo que desea hacer, Autodescubrimiento y trasformación mediante un aprendizaje e intercambio de valores.

Para transitar desde los recursos atractivos hasta la experiencia, incluyendo los productos y ofertas turísticas; hay pautas a seguir, que algunos autores han planteado y la tabla 2 sintetiza una selección. Estas propuestas, expresan maneras de actuar con autenticidad, que de acuerdo con SERNATUR (2016, p. 33) significa la oferta de situaciones, lugares, atractivos naturales, objetos y personas que, además de ser genuinos y originales, no han sido modificados o escenificados para los visitantes, existen independientemente de su presencia.

Tabla 2. Transitar a la experiencia

\begin{tabular}{|c|c|c|c|}
\hline $\begin{array}{l}\text { Pine \& } \quad \text { Gilmore } \\
(1998) .\end{array}$ & 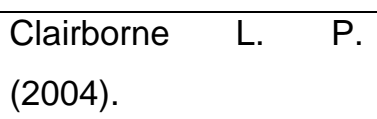 & SERNATUR (2016) & $\begin{array}{l}\text { Mogollón, González \& } \\
\text { Cerro (2020) }\end{array}$ \\
\hline $\begin{array}{l}\text { 1.Temar la } \\
\text { experiencia. } \\
\text { 2. Armonizar las } \\
\text { impresiones con } \\
\text { señales positivas. } \\
\text { 3. Elimina señales } \\
\text { negativas. } \\
\text { 4. Mézclalo en } \\
\text { recuerdos. } \\
\text { 5. Apliquen los cinco } \\
\text { sentidos. }\end{array}$ & $\begin{array}{l}\text { 1. Formar un equipo } \\
\text { de } \\
\text { diseño variado. } \\
\text { 2. Llegar al centro de } \\
\text { la } \\
\text { experiencia (a lo que } \\
\text { el cliente realmente } \\
\text { desea sentir al } \\
\text { combinar todas las } \\
\text { pistas). } \\
\text { 3. Centrarse en las } \\
\text { pistas. } \\
\text { 4. Fabricar un guion o } \\
\text { narración para la } \\
\text { experiencia. (describir } \\
\text { lo que el cliente } \\
\text { sentirá) } \\
\text { 5. Hacer una lista de }\end{array}$ & $\begin{array}{l}\text { 1.Conoce a tus } \\
\text { públicos. } \\
\text { 2.Conoce tu entorno. } \\
\text { 3. Conoce a tu } \\
\text { competencia. } \\
\text { 4. Define las bases de } \\
\text { tu experiencia: } \\
\text { a. Identifica } \\
\text { segmentos del público. } \\
\text { b. Identifica } \\
\text { necesidades del } \\
\text { público. } \\
\text { c. Define los objetivos } \\
\text { de la experiencia. } \\
\text { f. Define el guion de la } \\
\text { experiencia. } \\
\text { g. Evalúa un precio. } \\
\text { h. Revisa todos los }\end{array}$ & $\begin{array}{l}\text { 1. Basar las } \\
\text { experiencias en } \\
\text { atractivos naturales y } \\
\text { culturales } \\
\text { diferenciadores. } \\
\text { 2. Determinar el tipo } \\
\text { de experiencia de } \\
\text { acuerdo al segmento } \\
\text { de mercado. } \\
\text { 3. Asignar un tema a la } \\
\text { experiencia. } \\
\text { Incluir actividades } \\
\text { participativas y } \\
\text { vinculadas a la } \\
\text { comunidad local. } \\
\text { 4. Crear actividades o } \\
\text { eventos únicas del } \\
\text { destino. }\end{array}$ \\
\hline
\end{tabular}




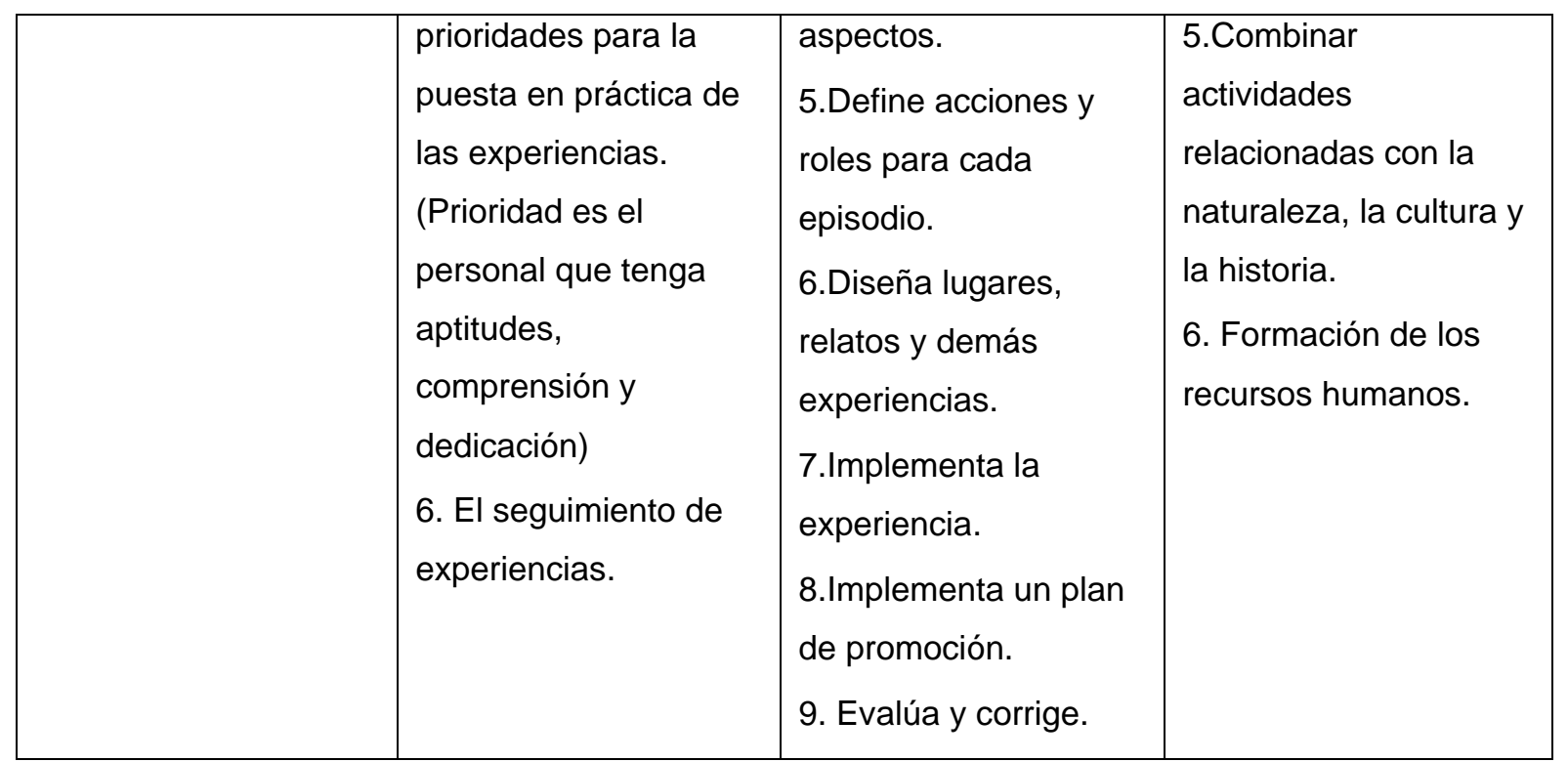

Fuente. Elaboración propia.

Mientras que las ofertas económicas previas - mercancías, bienes y servicios- son externas al comprador, las experiencias son intrínsecamente personales, existentes sólo en la mente de un individuo que ha estado involucrado en un nivel emocional, físico, intelectual o incluso espiritual (Pine \& Gilmore, 1998). La figura ejemplifica, como estos preceptos de hace 22 años se hacen comprensibles en la transición desde el recurso atractivo hasta la experiencia turística, partiendo de una diferenciación de los atributos de un espacio natural protegido, hasta la inclusión y participación personal del visitante. También ocurre que, en la actualidad, "aunque muchas empresas escenifiquen experiencias, la mayoría todavía están cobrando por sus bienes y servicios", esto ocurre en el caso de estudio que se muestra de ejemplo (Figura 4) donde se refleja que, en la actividad turística el recurso es diferente porque posee atracción para los visitantes de forma general, pero en el tránsito a la configuración de la experiencia, se realizan ajustes a la medida de cada excursionista o turista, mediante la participación; de forma individualizada cada consumidor activa sus sentidos y da un significado a su vivencia. 
Figura 4. Ejemplificación en el Pentágono del recurso atractivo a la experiencia

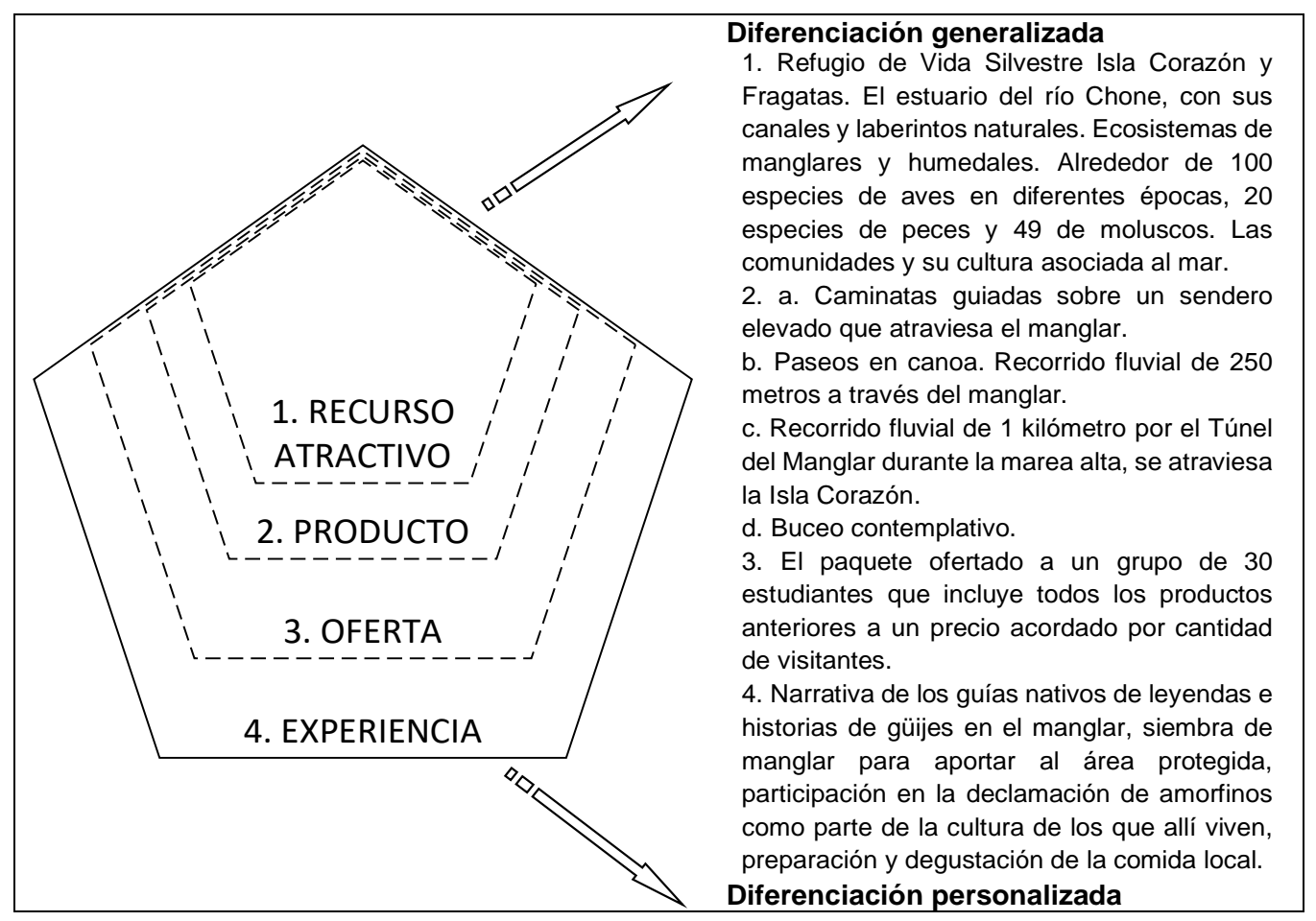

Fuente. Elaboración propia, la ejemplificación a partir de SNAP (2020) y una práctica de aplicación desarrollada con estudiantes de la carrera de Turismo de la ULEAM.

Las empresas crean ofertas más relevantes para los deseos y necesidades de los compradores individuales, diferencian sus bienes y servicios del mar de competidores similares y, por lo tanto, aumentan el valor proporcionado, y también el precio cobrado, a los usuarios y clientes (Pine \& Gilmore, 2012, p. 22). Los gerentes de turismo deben utilizar la capacitación del personal para equipar a sus empleados con la comprensión de las experiencias emocionales diversificadas y las estrategias para implementarlas (Wang, Hou, \& Chen, 2020, p. 16). Cuando el visitante consume a su medida, las vivencias y experiencias son más individualizadas, consecuentemente es mayor la satisfacción y la predisposición para pagar al precio exigido. El deseo de repetir lo vivido, adquiere relevancia, a la vez que se convierte en canal de comunicación, para que otros consuman.

\section{REFLEXIONES FINALES}

La claridad en las definiciones conceptuales que se asuman sienta las bases para direccionar los procesos de gestión en la actividad turística. En consecuencia, la compresión de la derivación y complejidad que adquiere la interpretación de conceptos como: recursos atractivos, productos, ofertas y experiencias; permitirá una mejor puesta en valor al consumidor, además, del enriquecimiento en el consumo de su itinerario. 
La materia prima de la actividad turística son aquellos recursos atractivos, que por ser diferentes y peculiares, tienen poder de atracción y estimulan el desplazamiento de los viajeros, en oposición de la a la materia prima indiferenciadas de otras actividades económicas.

El producto turístico expresa la combinación de todos aquellos componentes que hacen posible la puesta en valor de los recursos atractivos y agrupando varios, se ofertan al consumidor a un precio determinado, que depende de atributos o variables como la estacionalidad, los segmentos de mercados, la forma en que ha organizado el viaje, la demanda, entre otros factores.

En el diseño de las experiencias hay coincidencia, el eje es el consumidor, de modo que el estudio de los segmentos de mercados y de los intereses de excursionistas y turistas, determina la configuración. A lo anterior, se agrega la necesaria preparación del personal que gestiona la experiencia y las cualidades específicas que deben tener. La construcción de un guion, minuciosamente elaborado es la base del éxito, que se sostendrá en los recursos atractivos peculiares que estimulan la demanda. Las actividades diseñadas exigen la inmersión total de los participantes y de todos los órganos de los sentidos.

La modelación expresada en el "Pentágono del recurso atractivo a la experiencia", ilustra los niveles de subordinación de los conceptos abordados y desde posiciones teóricas intenta ejemplificar con la práctica vivida, la diferenciación en los términos, aspectos clave a considerar en los procesos de gestión turísticas, en consonancia con (Pearce 2014, p.141 y Pine \& Gilmore,1998).

Si bien, los recursos atractivos son la materia prima de la actividad turística, alrededor de los cuales se configura el producto y la oferta; los cambios de paradigmas exigen hoy, el diseño de experiencias donde la inserción del visitante en las actividades requiera el uso de todos los sentidos para que convierta la estancia en memorable.

\section{REFERENCIAS}

Almela, J. S. (2017). Sensoriality, cognition and affectivity in the language of tourism promotion: A corpus-based analysis of perceptive verbs. [Sensorialidad, cognición y afectividad en el lenguaje de promoción turística: Un análisis de corpus de los verbos de percepción] Circulo De Linguistica Aplicada a La Comunicacion, (72), 63-78. doi:10.5209/CLAC.57902

Ballina, B. F. J. D. L. (2018). Marketing turístico aplicado, ESIC Editorial. ProQuest Ebook Central Universidad Laica Eloy Alfaro de Manabí - Ecuador.

Bigné J. E., Font X. y Andreu L. (2000). Marketing de destinos turísticos: análisis y estrategias de desarrollo. Editorial ESIC. Madrid. España.

Birenboim, A. (2015): Nuevos enfoques para el estudio de las experiencias turísticas en el tiempo y el espacio, Geografías turísticas, DOI: 10.1080 / 14616688.2015.1122078

Boullón, R. C. (2006). Planificación del espacio turístico. -- 4a ed. -- México: Trillas, 245 p. ISBN 968-24-7562-7 
Clairborne L. P. (2004). Marketing de Experiencias. En el Libro: Clued In: How To Keep Customers Coming Back Again and Again. Editorial: Financial Times Prentice Hall. ISBN: 0131015508

Celdrán-Bernabeu, M. A., Mazón, J. -., \& Sánchez, D. G. (2018). Open data and tourism. implications for tourism management in smart cities and smart tourism destinations. [Open Data y turismo. Implicaciones para la gestión turística en ciudades y destinos turísticos inteligentes*] Investigaciones Turisticas, (15), 49-78. doi:10.14198/INTURI2018.15.03

Font Aranda, M. 2010. Metodología para el diseño de productos turísticos como alternativa de desarrollo local. Municipio Martí. Tesis presentada en opción al título de Master en Gestión Turística. Centro de Estudios de Turismo de Matanzas. Universidad de Matanzas, Cuba.

Fuentes, R., Moreno-Gil, S., González, C. Y Ritchie, B. (2015): "La creación y promoción de experiencias en un destino turístico. Un análisis de la investigación y necesidades de actuación", Cuadernos de Turismo, n 35, pp. 71-94.

Holbrook, M., \& Hirschman, E. (1982). The experiential aspects of consumption: consumer fantasies, feelings, and fun. Journal of Consumer Research, 9, 132-140.

Kuhn, F. (2020). Conspicuous souvenirs: Analysing touristic self-presentation through souvenir display. Tourist Studies, 20(4), 485-504. doi:10.1177/1468797620956935

Matos, H. (2005). Turismo. Complete su conocimiento. Escuela de Turismo Varadero. Obra protegida por el Centro Nacional de Derecho de Autor de la República de Cuba. Registro: 792005. Revisado el: 31 de marzo de 2005

Mogollón, J. M. H., González, B. S. P., \& Cerro, A. M. C. (2020). Application of the experiential approach to innovation in destination marketing: Recommendations for its implementation in ecuador. [L'application de l'approche expérientielle à l'innovation marketing dans les destinations touristiques: Des recommandations pour sa mise en œuvre en Equateur] Innovar, 30(77), 63-76. doi:10.15446/innovar.v30n77.87429

Olguín-Negrete, B. R., \& Cuevas-Contreras, T. (2019). Image of the destination among stakeholders and tourists: Hermosillo city, sonora, mexico. [Imagen del destino entre partes interesadas y turistas: Ciudad de Hermosillo, Sonora, México] Apuntes, 46(85), 141-167. doi:10.21678/apuntes.85.1048

Organización Mundial del Turismo (2019). Definiciones de turismo de la OMT. Published by the World Tourism Organization (UNWTO), Madrid, Spain, ISBN electronic: 978-92-844-2085-8. DOI: $10.18111 / 9789284420858$

Organización Mundial del Turismo (2020), Notas metodológicas de la base de datos de estadísticas de turismo, edición 2020, OMT, Madrid, DOI : https://doi.org/10.18111/9789284421473 .

Pearce, D. G. (2014). Toward an Integrative Conceptual Framework of Destinations. Journal of Travel Research, 2014, Vol. 53(2) 141 -153. doi:10.1177/0047287513491334. 
Philip Kotler, de Madariaga J. G., Zamora J. F., Bowen J. T, Makens J. C. (2011) Marketing Turístico 5. Ed. Pearson Educación, S.A., Madrid, 2011. ISBN: 978-84-8322-808-1

Pine II., B. J., \& Gilmore, J. H. (1998). Welcome to the experience economy. Harvard Business Review, 76(4), 97-105. Retrieved from www.scopus.com. https://hbr.org/1998/07/welcome-tothe-experience-economy?language $=e s$

Pine II., B. J., \& Gilmore, J. H. (2012) The experience economy: past, present and future. Handbook on the experience economy. Editors: Sundbo, Jon and Sørensen, Flemming DOI: $10.4337 / 9781781004227.00007$

Riquelme, P. M. (2019). Tourist spaces: Production, experiences and imagination. the case of the Andean-Chilean Andean lake area of la Araucanía, 1900-1940. [Los espacios turísticos: Producción, experiencias e imaginarios. el caso de la Araucanía Andino-lacustre Chilena, 1900-1940] Cuadernos de Turismo, (44), 219-246. doi:10.6018/turismo.44.404821

Rodríguez Fariña, R. 2005. Gestión de Destinos turísticos. Universidad de La Habana. En soporte electrónico.

Sancho, A. (1998). Introducción al turismo. Madrid: World Tourism Organisation.

SECTUR (Secretaría de Turismo). (2001). Integración de Agrupamientos Turísticos Competitivos

"Clusters Turísticos". Programa de Competitividad. Col. Chapultepec Morales C. P. 11580. México, D. F.

SERNATUR - Servicio Nacional de Turismo. (2016). Manual de diseño Experiencias Turísticas. Subdirección de Desarrollo, Unidad de Productos. Primera Edición. Ministerio de Economía Fomento y Turismo. Gobierno de Chile. Santiago de Chile.

Serra, A. (2011). Marketing Turístico (2 $2^{\underline{a}}$ Ed.) (En Papel). Editorial: Pirámide. ISBN: 9788436824742.

Sistema Nacional de Áreas Protegidas (SNAP). (2020). Refugio de Vida Silvestre Islas Corazón y Fragatas. Consultado noviembre 2020. Ministerio de Ambiente del Ecuador. Disponible en http://areasprotegidas.ambiente.gob.ec/es/node/136

Vera, J. F.F. López Palomeque, M. Marchena, y S. Antón 1997. Análisis Territorial del Turismo. Una nueva Geografía del Turismo, Editorial Ariel, Barcelona, 443 pp.

Wang, L., Hou, Y., \& Chen, Z. (2020). Are rich and diverse emotions beneficial? the impact of emodiversity on tourists' experiences. Journal of Travel Research, doi:10.1177/0047287520919521

Żemła, M., \& Siwek, M. (2020). Between authenticity of walls and authenticity of tourists' experiences: The tale of three polish castles. Cogent Arts and Humanities, 7(1) doi:10.1080/23311983.2020.1763893 